\title{
The implication of Thorium fraction on neutronic parameters of pebble bed reactor
}

\author{
Zuhair*, R. Andika Putra Dwijayanto, Suwoto, Topan Setiadipura \\ Center for Nuclear Reactor Technology and Safety - BATAN \\ Puspiptek Complex, OB No. 80, Serpong, Tangerang Selatan 15310, Indonesia \\ *Corresponding author: zuhair@batan.go.id
}

\begin{abstract}
Thorium abundance in the Earth's crust is estimated to be three to four times higher than uranium. This is one potential advantage of Thorium as a provider of attractive fuel to produce nuclear energy. Fewer transuranics produced by Thorium during the fuel burn up in the reactor may also be another advantage for reducing the long-term burden of high-level long-lived waste. The scope of this paper is to study the implication of Thorium fraction on neutronic parameters of pebble bed reactor. The reactor model of HTR-10 was selected, and the (Th, ${ }^{235} \mathrm{U} \mathrm{O}_{2}$ fuel was used in this study. The MCNP6 code was applied to solve a series of neutron transport calculations with various Thorium fractions in $\left(\mathrm{Th},{ }^{235} \mathrm{U}\right) \mathrm{O}_{2}$ fuel based on the ENDF/BVII library. The calculation results show that the total temperature coefficient of reactivity of Thorium-added pebble bed reactors is generally more negative than those of LEU-fuelled one, except for $10 \%$ Thorium fraction. The kinetic parameters, especially prompt neutron lifetime and neutron generation time of pebble bed reactors, are higher, which means the addition of Thorium in the fuel makes the reactor more easily controlled. However, the burn-up calculations show that the introduction of Thorium in the same fuel kernel as LEU within the pebble bed reactor is unable to lengthen the fuel residence time, except for a minimum of $40 \%$ Thorium fraction.
\end{abstract}

Keywords: ENDF/B-VII; MCNP6; neutronic parameter; pebble bed reactor; Thorium.

\section{Introduction}

Thorium abundance in the Earth's crust is estimated to be three to four times higher than Uranium. It is a potential advantage for Thorium as a provider of attractive fuel to generate nuclear power. Fewer transuranics produced by Thorium during the fuel burn up in the reactor is also another advantage for reducing the long-term burden of long-lived radioactive waste. The material properties of Thorium differ from those of Uranium. Compared to $\mathrm{UO}_{2}$, Thorium in the chemical form of $\mathrm{ThO}_{2}$ has favourable thermophysical properties obtained from its lower coefficient of thermal expansion and higher thermal conductivity. $\mathrm{ThO}_{2}$ has a higher melting point $\left(3370^{\circ} \mathrm{C}\right)$ compared with that of $\mathrm{UO}_{2}$ $\left(2840^{\circ} \mathrm{C}\right)$. These beneficial properties make it reasonable to assume that $\mathrm{ThO}_{2}$-based nuclear fuel has good performance in HTGR operation with high burnup and very high temperature (GIF, 2010).

Thorium is a naturally occurring radioactive element almost entirely composed of the ${ }^{232} \mathrm{Th}$ isotope. Since ${ }^{232} \mathrm{Th}$ is fertile, it cannot induce fission directly from thermal neutron capture. Similarly, as Thorium has no naturally occurring fissile isotope, it cannot be enriched the same way Uranium is enriched. Thorium, however, plays an important role as a fertile isotope much like ${ }^{238} \mathrm{U}$, if not for better. ${ }^{232} \mathrm{Th}$ transmutes into ${ }^{233} \mathrm{U}$, a good nuclear fuel when it captures a neutron. Unlike ${ }^{239} \mathrm{Pu}$, which is transmuted from ${ }^{238} \mathrm{U},{ }^{233} \mathrm{U}$ performs better than ${ }^{235} \mathrm{U}$ in the thermal spectrum due to higher neutron per fission and lower capture cross-section. Using Thorium in a nuclear reactor requires a fissile isotope to provide neutrons for ${ }^{233} \mathrm{U}$ 
transmutation. The available fissile options are ${ }^{235} \mathrm{U},{ }^{239} \mathrm{Pu}$, and ${ }^{233} \mathrm{U}$. Introducing these isotopes into Thorium can be done by combining and mixing them with the Thorium to form nuclear fuel in oxide $\left[\left(\mathrm{Th},{ }^{233} \mathrm{U}\right) \mathrm{O}_{2},\left(\mathrm{Th},{ }^{235} \mathrm{U}\right) \mathrm{O}_{2}\right.$, and $\left(\mathrm{Th},{ }^{239} \mathrm{Pu}\right)$ $\left.\mathrm{O}_{2}\right]$ or carbide $\left[\left(\mathrm{Th},{ }^{233} \mathrm{U}\right) \mathrm{C},\left(\mathrm{Th},{ }^{235} \mathrm{U}\right) \mathrm{C}\right.$, and $\left(\mathrm{Th},{ }^{239} \mathrm{Pu}\right) \mathrm{C}$ ] compounds (Björk, 2015; Gintner, 2010).

The scope of this paper is to study the implication of Thorium fraction on neutronic parameters of pebble bed reactor. The reactor model of HTR-10 (Wu et al., 2002) was selected in this study due to the fairly complete data regarding its design, specification, and characteristics, which is important for developing the desired computation model. The $\left(\mathrm{Th},{ }^{235} \mathrm{U}\right) \mathrm{O}_{2}$ fuel was used in this study because its feasibility has been demonstrated in almost all types of nuclear reactors. The two boiling water reactors (BWRs) BORAX IV and Elk River in the USA utilized high density $\left(\mathrm{Th},{ }^{235} \mathrm{U}\right) \mathrm{O}_{2}$ fuel. The pebble bed typed high temperature gas-cooled reactors (HTGRs) have adopted this fuel in German Arbeitsgemeinschaft
Versuchsreaktor (AVR) and ThoriumHochtemperaturreaktor (THTR). The $\left(\mathrm{Th},{ }^{235} \mathrm{U}\right) \mathrm{O}_{2}$ fuel has also been employed in the prismatic block typed HTGRs Peach Bottom and Fort St Vrain in the USA. In Canada, the material testing reactors (MTRs) NRU and NRX with pin assemblies have accommodated this fuel for irradiation and testing of few fuel elements (IAEA-TECDOC-1450, 2005).

The Monte Carlo transport code MCNP6 (Goorley et al., 2013) was applied to solve a series of neutron transport calculations with different Thorium fractions in $\left(\mathrm{Th},{ }^{235} \mathrm{U}\right) \mathrm{O}_{2}$ fuel based on nuclear data library ENDF/BVII (Chadwick et al., 2006). The neutronic parameters calculated include effective multiplication factor $\left(\mathrm{k}_{\text {inf }}\right)$, temperature coefficient of reactivity, and kinetic parameters. The concentration of several important isotopes resulting from fuel burnup was estimated using CINDER90 (Wilson et al., 2006) depletion module integrated with MCNP6. The calculation results were summarized to complete an inter-comparison analysis of core physics parameters with different Thorium fractions.

Table 1. General design characteristic of HTR-10 (Jing \& Sun, 1998).

Reactor nomial power (MWt)

Reactor design

Inlet/outlet helium temperature $\left({ }^{\circ} \mathrm{C}\right)$

Helium pressure (MPa)

Helium flow rate $(\mathrm{kg} / \mathrm{s})$

Number of control rods

Number of small absorber balls

Number of irradiation experiment

Core diameter / height $(\mathrm{cm})$

Core specification

The volume of active core $\left(\mathrm{m}^{3}\right)$

Fuel to moderator pebbles ratio

Number of pebbles in full core 
Tabel 2. General specification of fuel pebble.

\begin{tabular}{|c|c|c|c|}
\hline \multicolumn{4}{|c|}{ Fuel pebble } \\
\hline The radius of $p$ & & & 3 \\
\hline \multicolumn{3}{|c|}{ The radius of the fuel zone $(\mathrm{cm})$} & 2.5 \\
\hline \multicolumn{3}{|c|}{ The thickness of the graphite shell } & 0.5 \\
\hline \multicolumn{3}{|c|}{ The density of graphite matrix and shell $\left(\mathrm{g} / \mathrm{cm}^{3}\right)$} & 1.73 \\
\hline \multicolumn{3}{|c|}{ Impurity of natural boron in a graphite matrix and shell (ppm) } & 1.3 \\
\hline \multicolumn{4}{|c|}{ TRISO fuel particle } \\
\hline \multicolumn{3}{|c|}{ Number of TRISO particles in fuel pebble } & 8,335 \\
\hline TRISO packing & & & 5.025 \\
\hline \multicolumn{4}{|c|}{ 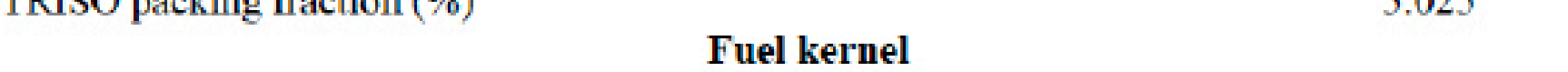 } \\
\hline \multicolumn{3}{|l|}{ Material } & $\left(\mathrm{Th},{ }^{235} \mathrm{U}\right) \mathrm{O}_{2}$ \\
\hline \multicolumn{3}{|l|}{ Diameter $(\mathrm{cm})$} & 0.050 \\
\hline \multicolumn{3}{|l|}{ Density $\left(\mathrm{g} / \mathrm{cm}^{3}\right)$} & 10.41 \\
\hline \multirow{2}{*}{\multicolumn{3}{|c|}{$\begin{array}{l}\text { Th fraction in fuel (\%) } \\
\text { Boron impurity in fuel kemel (ppm) }\end{array}$}} & $0-50$ \\
\hline & & & 1.3 \\
\hline \multicolumn{4}{|c|}{ Coating layer } \\
\hline & Material & Thickness $(\mathrm{cm})$ & Density $\left(\mathrm{g} / \mathrm{cm}^{3}\right)$ \\
\hline Buffer & $\mathrm{C}$ & 0.0090 & 1.10 \\
\hline iPyC & $\mathrm{C}$ & 0.0040 & 1.90 \\
\hline $\mathrm{SiC}$ & $\mathrm{SiC}$ & 0.0035 & 3.18 \\
\hline oPyC & $\mathrm{C}$ & 0.0040 & 1.90 \\
\hline
\end{tabular}

\section{Materials and methods}

\subsection{HTR-10 description}

HTR-10 is the reference design used in the current study. It is a pebble bed reactor with helium as coolant and graphite as a moderator and a structural material. General design and core characteristics are shown in Tables 1 and 2.

To investigate the effect of the thorium, in the current study, the TRISO particle comprises a spherical fuel kernel of $\left(\mathrm{Th}^{235} \mathrm{U}\right) \mathrm{O}_{2}$ with a radius of $0.025 \mathrm{~cm}$ coated by layers of porous carbon buffer(C), inner pyrolytic carbon (iPyC), silicon carbide $(\mathrm{SiC})$ and outer pyrolytic carbon (oPyC). The thickness data of each layer are $0.009 \mathrm{~cm}, 0.004 \mathrm{~cm}, 0.0035 \mathrm{~cm}$, and $0.004 \mathrm{~cm}$, respectively. The buffer layer is functioned to provide a space for localizing and retaining the gaseous fission products. The other three layers are designed to provide a barrier for fission product release even at a very high temperature of $1600{ }^{\circ} \mathrm{C}$. Figure 1 shows the configuration of pebble fuel.

Natural Thorium was used in $\left(\mathrm{Th}^{235} \mathrm{U}\right) \mathrm{O}_{2}$ fuel with fraction varied from $0 \%$ to $50 \%$. The fuel with $0 \%$ Thorium fraction is treated as the same as current HTR-10 fuel, which is 17\%-enriched $\mathrm{UO}_{2}$ fuel. Various Thorium fractions in $\left(\mathrm{Th},{ }^{235} \mathrm{U}\right)$ $\mathrm{O}_{2}$ fuel is intended to analyze the implications of different fuel compositions on the neutronic parameters of the pebble bed reactor. A study showed that a $30 \%$ Thorium fraction for a $15 \%$ ${ }^{235} \mathrm{U}$ enriched fuel was the optimum fraction, and the optimum fraction decreased for lower ${ }^{235} \mathrm{U}$ enrichment (Irwanto et al., 2012). Besides, this study also showed that a Thorium fraction of more than $50 \%$ gave a significant reduction in the burn-up performance of the core. Based on this finding, a maximum of $50 \%$ Thorium fraction was set in the current study. An interval of $10 \%$ was enough to represent the physical trend of Thorium fraction impact of the neutronic properties of the core. 


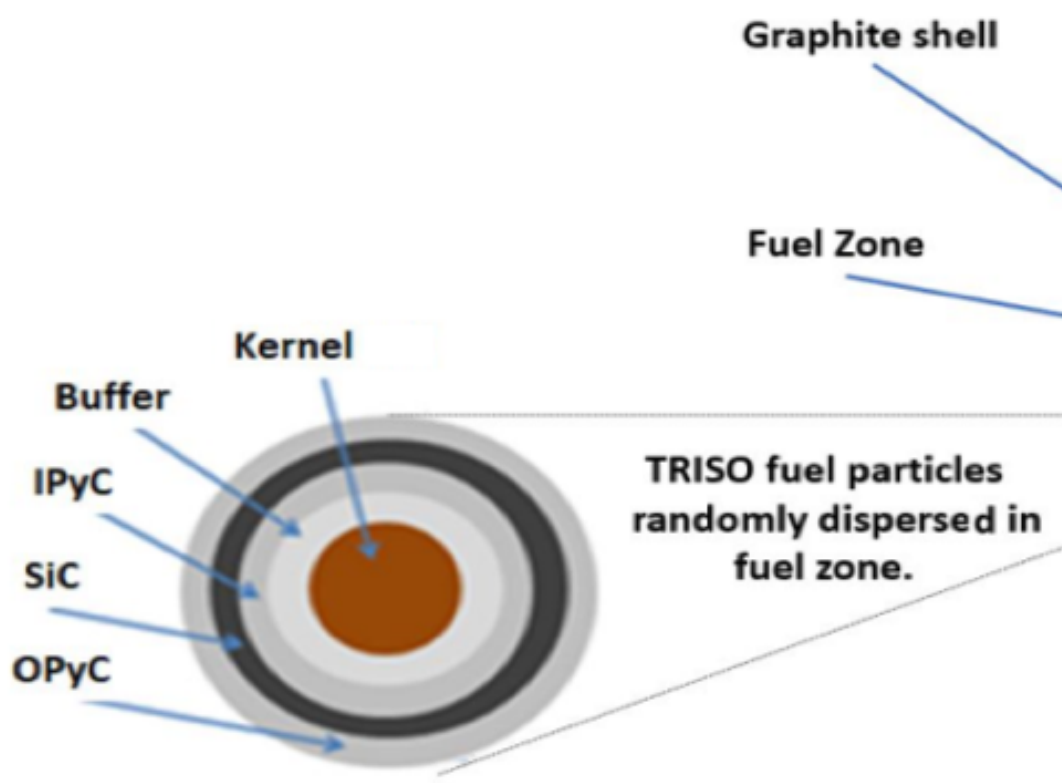

TRISO fuel particle

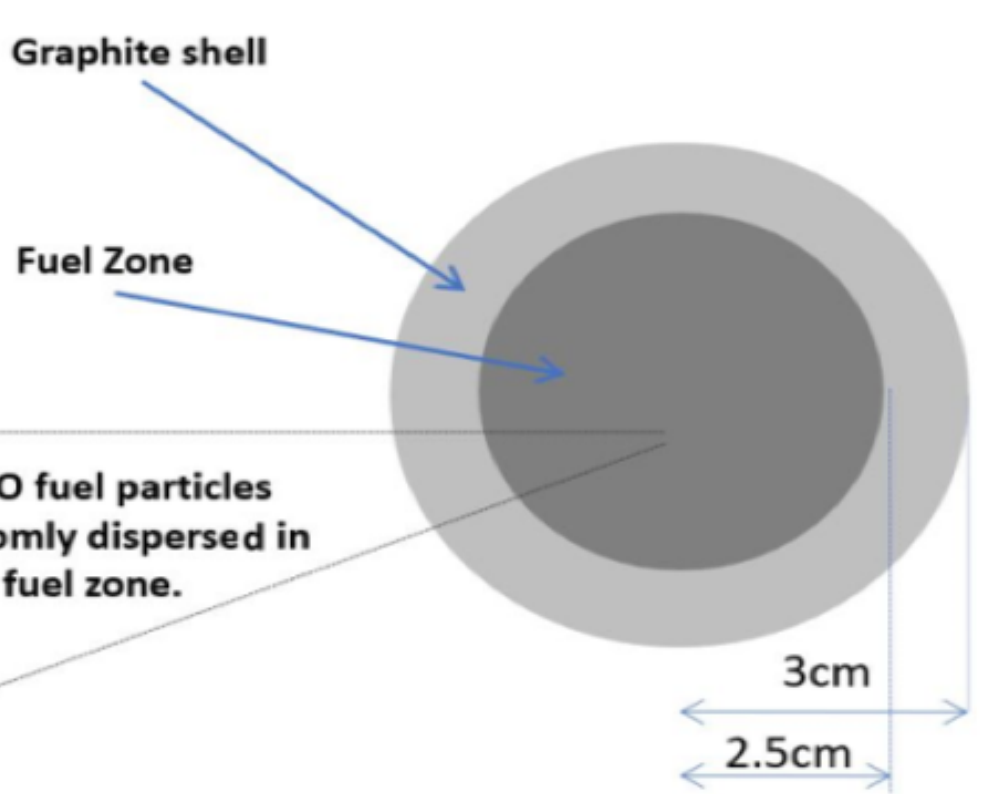

Pebble fuel element

Fig. 1. Configuration of fuel pebble (Setiadipura et al., 2015).

\subsection{Calculation model}

The modeling of the pebble bed reactor should consider the double heterogeneity features characterized by the random distribution of both TRISO particles in fuel pebble and the pebbles within the reactor core. MCNP6 offers complex geometry modeling capabilities with high accuracy 3-D calculations of the physical system; thus, it can treat the double heterogeneity problem. MCNP6 is the latest Monte Carlo transport code representing the culmination of many years of efforts to combine all features of MCNP5 and MCNPX codes into one product.
2.2.1 Fuel pebble model

Fuel pebble modeling was preceded by modeling the TRISO particles. Fuel kernel and its coating layers were placed in the center of a simple cubic (SC) lattice with exact dimensions. The SC lattice was chosen because its simplicity and calculation difference with other lattices (BCC, FCC, HCP) are not significant (Wahid et al., 2019). The square pitch of the cubic lattice was calculated to be $0.1988 \mathrm{~cm}$ which corresponds to the TRISO packing fraction of $5.0248 \%$. The graphite matrix where TRISO particles are embedded was modeled to occupy a remaining space outside the TRISO particles.

Table 3. Atomic densities of $\left(\mathrm{Th},{ }^{235} \mathrm{U}\right) \mathrm{O}_{2}$ fuel kernel.

\begin{tabular}{||cccccc|}
\hline $\begin{array}{c}\text { Th fraction } \\
(\%)\end{array}$ & ${ }^{230} \mathrm{Th}$ & ${ }^{232} \mathrm{Th}$ & $235 \mathrm{U}$ & $238 \mathrm{U}$ & $16 \mathrm{O}$ \\
0 & - & - & $3.9920 \times 10^{-3}$ & $1.9244 \times 10^{-2}$ & $4.6473 \times 10^{-2}$ \\
10 & $4.7975 \times 10^{-7}$ & $2.3776 \times 10^{-3}$ & $3.5919 \times 10^{-3}$ & $1.7315 \times 10^{-2}$ & $4.6570 \times 10^{-2}$ \\
20 & $9.5923 \times 10^{-7}$ & $4.7538 \times 10^{-3}$ & $3.1919 \times 10^{-3}$ & $1.5387 \times 10^{-2}$ & $4.6667 \times 10^{-2}$ \\
30 & $1.4384 \times 10^{-6}$ & $7.1287 \times 10^{-3}$ & $2.7921 \times 10^{-3}$ & $1.3460 \times 10^{-2}$ & $4.6764 \times 10^{-2}$ \\
40 & $1.9174 \times 10^{-6}$ & $9.5022 \times 10^{-3}$ & $2.3926 \times 10^{-3}$ & $1.1534 \times 10^{-2}$ & $4.6861 \times 10^{-2}$ \\
50 & $2.3961 \times 10^{-6}$ & $1.1874 \times 10^{-2}$ & $1.9932 \times 10^{-3}$ & $9.6087 \times 10^{-3}$ & $4.6958 \times 10^{-2}$ \\
\hline
\end{tabular}


The model of fuel pebble was constructed by expanding the SC lattice using a repetitive structure so that 8,335 TRISO particles fill the fuel zone of the pebble. The graphite shell was modeled, wrapping the fuel zone to form complete modeling of fuel pebble. Since the packing fraction is small, the TRISO particles in the fuel pebble are relatively distant from each other. The effect of truncated TRISO at the surface between the fuel zone and graphite shell caused by repetitive structure can be ignored. The atomic densities of $\left(\mathrm{Th},{ }^{235} \mathrm{U}\right) \mathrm{O}_{2}$ fuel kernel with various Thorium fractions are given in Table 3.

\subsubsection{Reactor core model}

Similar to the fuel pebble model, the reactor core model starts by modeling the pebbles. In this case, BCC lattice was used. Two pebbles in the BCC lattice consist of eight partial moderator pebbles (1/8 pebbles each) at the eight corners and one fuel pebble at the lattice center. The radius of the moderator pebble was adjusted to be $2.731 \mathrm{~cm}$ from its actual radius of $3 \mathrm{~cm}$ to preserve the fuel to moderator pebbles ratio of 57/43 unchanged. The BCC lattice's square pitch was adjusted to be $6.8772 \mathrm{~cm}$ to control the distance between the pebbles defined by a packing fraction of 0.61 . The moderator pebbles in the cone area were modeled using BCC lattice also with the same packing fraction of 0.61 . The reactor core model containing 27,000 pebbles was constructed by expanding the BCC lattice using a repetitive structure. The truncated pebble at the surface of the reactor core resulted by repetitive structure was eliminated by creating an exclusive zone of $1.71 \mathrm{~cm}$ helium encircling the reactor core. The moderator pebbles in the cone area were modeled using the BCC lattice with its actual radius at the center of the lattice and radius of $2.731 \mathrm{~cm}$ at the eight corners of the lattice. The combination of three geometry options of LATTICE, FILL, and UNIVERSE provided by MCNP6 was utilized to model fuel pebble and model the reactor core.
The main components of the reactor, such as 20 helium riser columns in the side reflector, 10 control rod columns, 7 absorber ball columns, and 3 experimental columns for irradiation, were modeled using basic surface types of cylinders, planes, and pads according to their geometry and dimensions without assumptions and simplifications. The combination of three geometry options of FILL, UNIVERSE, and TRCL was utilized to model reactor components. The fuel discharge tube and the reflector consisting mostly of boronated carbon block were also modeled in detail. This modeling methodology was developed and already validated using several critical experiments (Lebenhaft, 2001) and has been demonstrated in numerous publications (Alzamly et al., 2020; Zuhair et al., 2020; Zuhair et al., 2019a; Zuhair et al., 2019b; Hosseini \& Athari-Allaf, 2016; Hosseini \& Athari-Allaf, 2012). The fuel pebble model and reactor core model are illustrated in Figures 2 and 3 , respectively.

To solve the criticality problem, in addition to the geometry description and material cards, the KCODE and the KSRC cards are required. These are two main control cards used to specify the MCNP6 criticality source for determining the effective multiplication factor (left) and specify the location of the starting point source for a KCODE calculation, respectively. In the KCODE card, a nominal source size of 10,000 neutron histories, a $\mathrm{k}_{\mathrm{inf}}$ estimation of 1.0, a skipped initial cycle of 50 , and a total running of 250 cycles were simulated. The skipped cycle was used to ensure convergence before starting the average calculation from one cycle to the next cycle. The initial spatial distribution of source points was randomly located inside the fissile materials in the geometry of the reactor. The thermal neutron scattering data $S(\alpha, \beta)$ was applied to take into account the molecular binding affinity in all materials containing graphite which interacts with thermal neutron at the energy region below $\sim 4 \mathrm{eV}$. The outer boundary condition of the pebble bed reactor was defined to be under vacuum condition. All control rods were set at a full withdrawal position. 


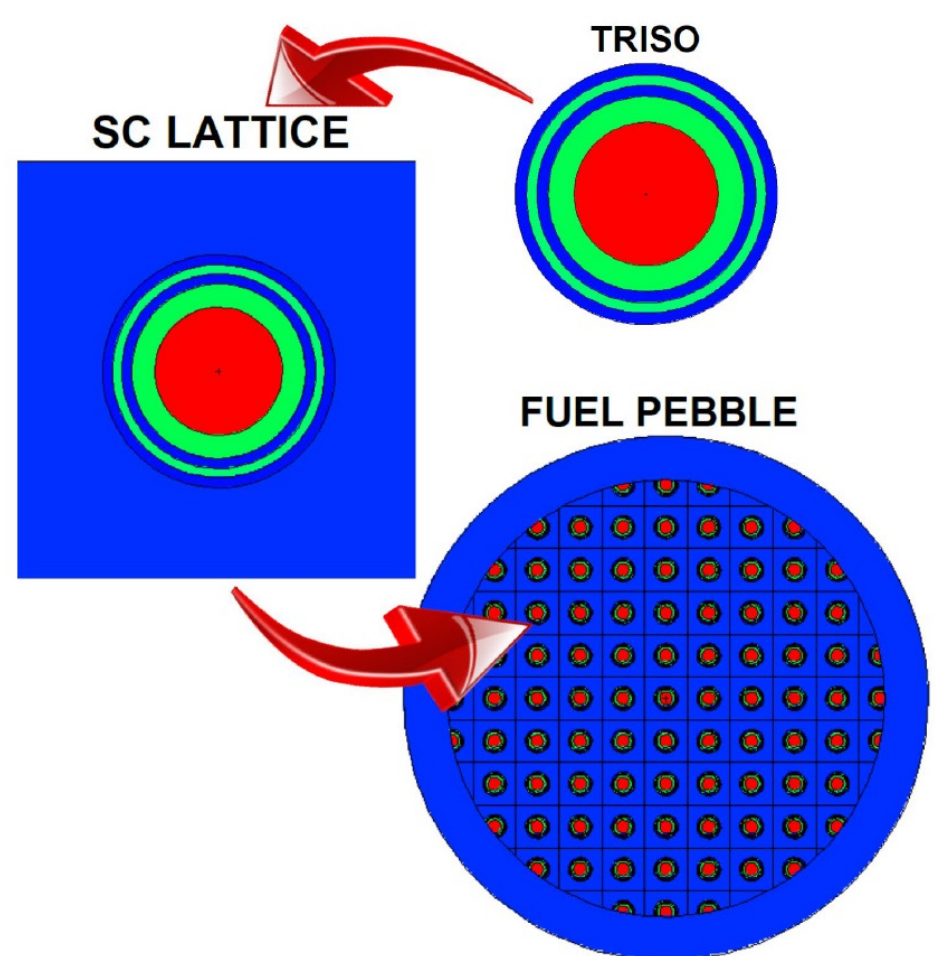

Fig. 2. Fuel pebble model.

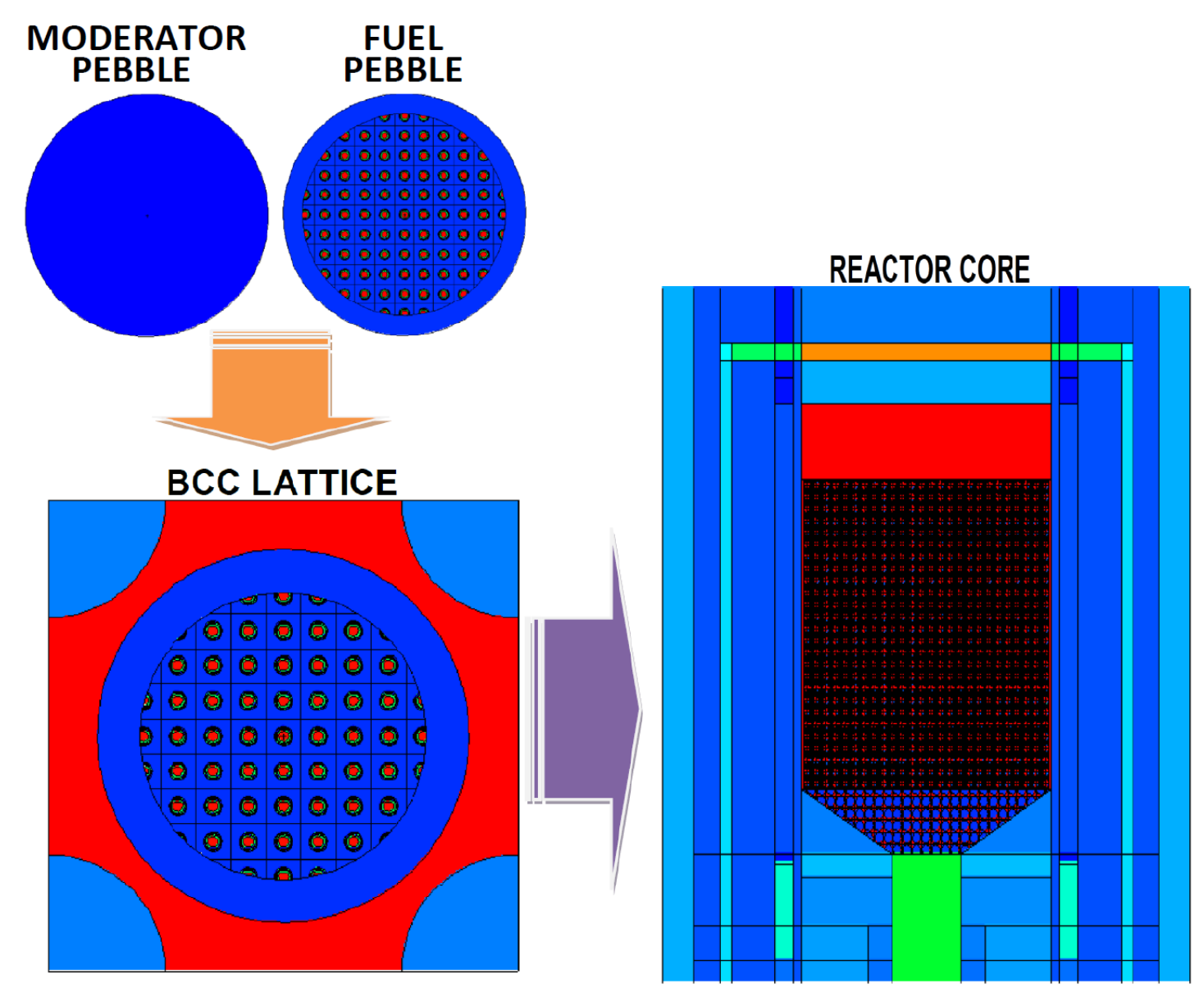

Fig. 3. Reactor core model. 


\section{Results and discussion}

The calculation results of the effective multiplication factor $\left(\mathrm{k}_{\text {inf }}\right)$ as the function of the Th fraction are illustrated in Figure 4. For all fractions, the $\mathrm{k}_{\text {inf }}$ value decreases as the temperature rises. This implies that Thorium addition in the reactor can still maintain a negative temperature coefficient of reactivity (TCR). Furthermore, it was observed that there is a slight increase in negative TCR in most fractions of Thoriumadded fuel. The figure shows that the LEUfueled pebble bed reactor has the highest $\mathrm{k}_{\text {inf }}$ value compared to Thorium-added ones. The problem is that Thorium-added fuel necessitates the reduction of fissile ${ }^{235} \mathrm{U}$, exacerbated by a higher capture crosssection of Th compared to ${ }^{238} \mathrm{U}$. Thus, $50 \%$ Th fraction understandably has the lowest initial $\mathrm{k}_{\mathrm{inf}}$. This happens in most Thoriumfueled reactors, even if the fissile content is kept the same.

Table 4 shows the calculation results of the temperature coefficient of reactivity (TCR) as the function of Thorium fraction. As previously mentioned, a higher Thorium fraction provides more negative TCR. This is especially true for the fuel temperature coefficient (FTC), which is more negative for all Thorium fractions. Meanwhile, moderator temperature coefficient (MTC) is comparatively less negative in thoriumadded pebbled bed reactor up to $30 \%$ of Thorium fraction. The MTC is more negative in subsequent fractions. Nevertheless, the less negative MTC is compensated by more negative FTC so that the TCR value of Thorium-added reactors is generally more negative than the LEU-fuelled pebble bed reactor. For exception is at $10 \%$ Thorium fraction, which TCR is less negative.

This finding is interesting because, in other studies, Thorium addition is found to be reducing the negative value of TCR (Suwoto et al., 2018; Xia \& Li, 2013). Meaning, TCR of Thorium-added pebble bed reactors are less negative than LEU-only reactor. This difference is caused by a reduction in fissile load due to increased Thorium fraction. As the fissile load becomes smaller and the Thorium fraction becomes higher, a smaller fission neutron is absorbed more due to Doppler broadening. However, different TCR characteristics may appear if the fissile load is not altered, i.e., kept the same for all thorium fractions. This possibility must be assessed in future works.

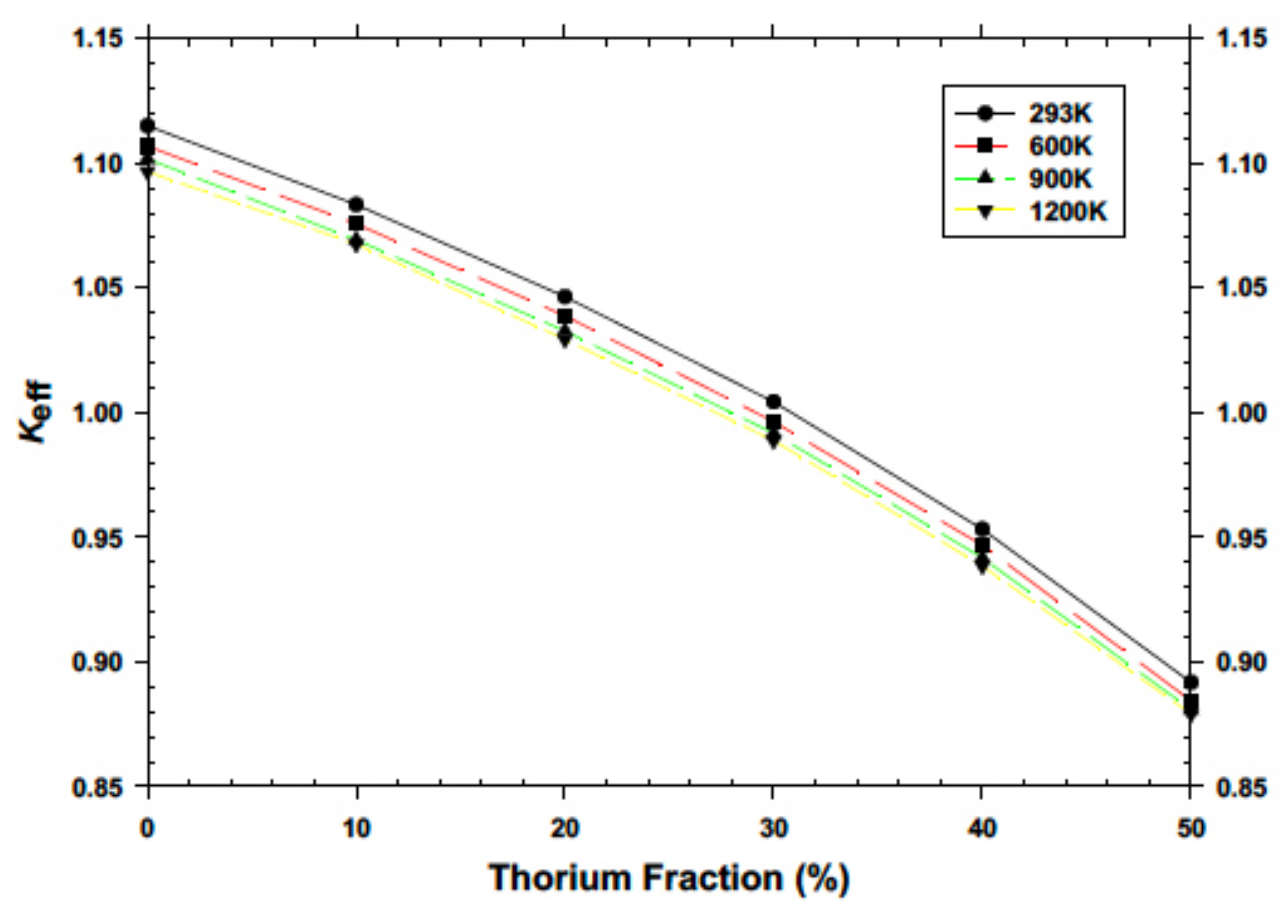

Fig. 4. Effective multiplication factor $\left(\mathrm{k}_{\mathrm{eff}}\right)$. 
Table 4. Temperature coefficient of reactivity.

\begin{tabular}{||ccc|}
\hline \hline Th fraction $(\%)$ & $\begin{array}{c}\text { Fuel temperature coefficient of } \\
\text { reactivity }(\mathrm{FTC}, \% \Delta \mathrm{k} / \mathrm{k})\end{array}$ & $\begin{array}{c}\text { Moderator temperature } \\
\text { coefficient of reactivity (MTC, } \\
\% \Delta \mathrm{k} / \mathrm{k})\end{array}$ \\
0 & $-1.49759 \pm 0.00063$ & $-0.12452 \pm 0.00063$ \\
10 & $-1.50838 \pm 0.00055$ & $-0.04625 \pm 0.00057$ \\
20 & $-1.55688 \pm 0.00055$ & $-0.08614 \pm 0.00055$ \\
30 & $-1.58196 \pm 0.00058$ & $-0.10025 \pm 0.00055$ \\
40 & $-1.64961 \pm 0.00057$ & $-0.14534 \pm 0.00058$ \\
50 & $-1.67050 \pm 0.00055$ & $-0.18893 \pm 0.00055$ \\
\hline
\end{tabular}

Table 5. Kinetic parameters.

\begin{tabular}{||cccc|}
\hline \hline $\begin{array}{c}\text { Th } \\
\text { fraction } \\
(\%)\end{array}$ & $\begin{array}{c}\text { Effectively delayed } \\
\text { neutron fraction }\left(\beta_{\text {eff }}\right)\end{array}$ & $\begin{array}{c}\text { Prompt neutron } \\
\text { lifetime }(\ell, \mathrm{s})\end{array}$ & $\begin{array}{c}\text { Neutron generation } \\
\text { time }(\Lambda, \mathrm{s})\end{array}$ \\
0 & $0.00668 \pm 0.00066$ & $2.2599 \times 10^{-3} \pm 1.6658 \times 10^{-6}$ & $1.34825 \times 10^{-3} \pm 1.351 \times 10^{-5}$ \\
10 & $0.00725 \pm 0.00070$ & $2.3504 \times 10^{-3} \pm 1.5504 \times 10^{-6}$ & $1.48911 \times 10^{-3} \pm 1.472 \times 10^{-5}$ \\
20 & $0.00681 \pm 0.00064$ & $2.4568 \times 10^{-3} \pm 1.6620 \times 10^{-6}$ & $1.66371 \times 10^{-3} \pm 1.610^{-3} \times 10^{-5}$ \\
30 & $0.00645 \pm 0.00061$ & $2.5867 \times 10^{-3} \pm 1.7747 \times 10^{-6}$ & $1.85601 \times 10^{-3} \pm 1.736 \times 10^{-5}$ \\
40 & $0.00710 \pm 0.00071$ & $2.7432 \times 10^{-3} \pm 1.8522 \times 10^{-6}$ & $2.16895 \times 10^{-3} \pm 2.117 \times 10^{-5}$ \\
50 & $0.00723 \pm 0.00075$ & $2.9390 \times 10^{-3} \pm 1.8903 \times 10^{-6}$ & $2.60103 \times 10^{-3} \pm 2.533 \times 10^{-5}$ \\
\hline \hline
\end{tabular}

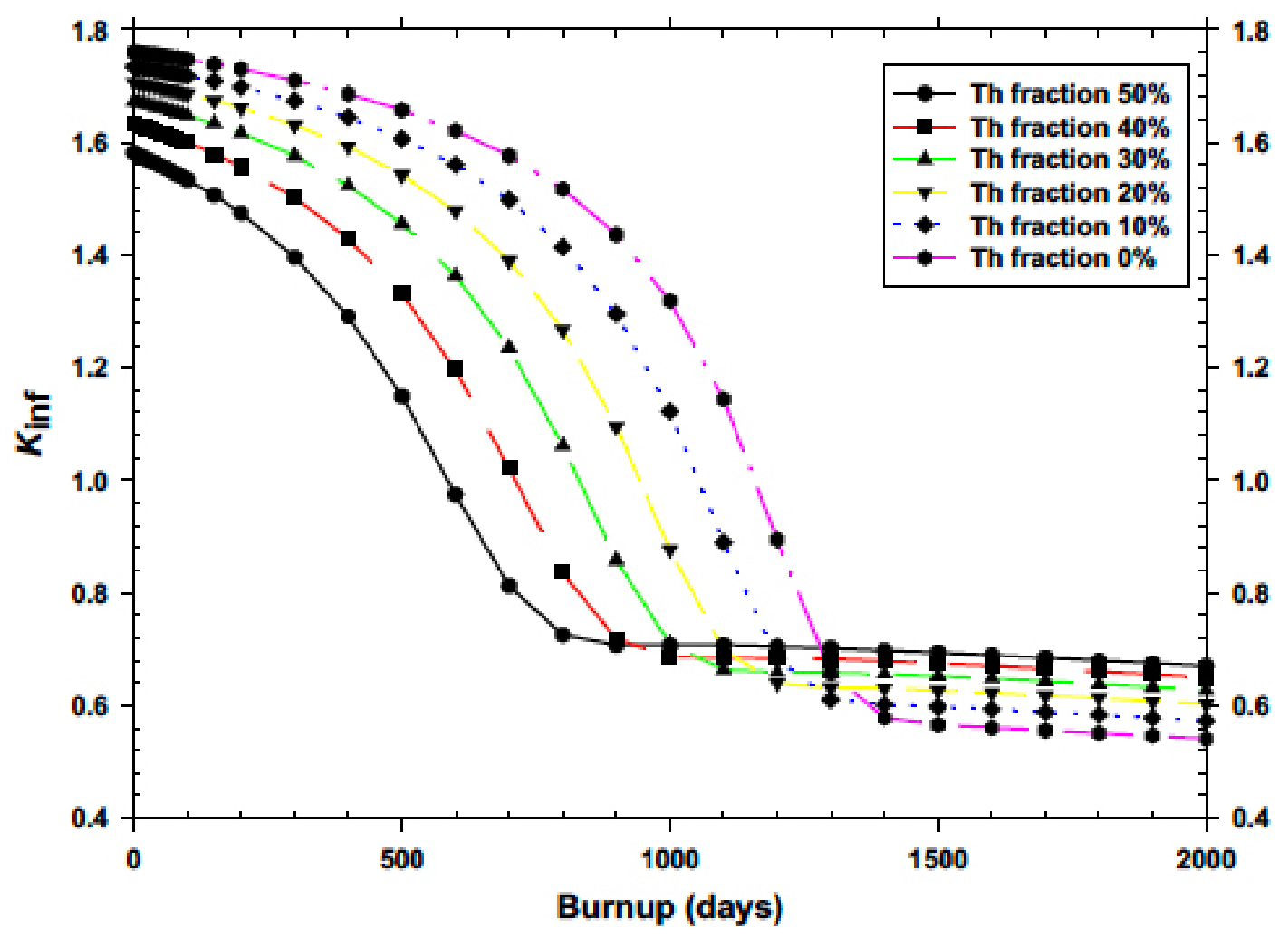

Fig. 5. Infinite multiplication factor $\left(\mathrm{k}_{\text {inf }}\right)$. 
As for kinetic parameters, as shown in Table 5, the calculation results of $\beta_{\text {eff }}$ do not show any particular pattern. Most of the values lie well above $\beta$ fraction of ${ }^{235} \mathrm{U}$ except Thorium fraction of $30 \%$. MCNP6 considers uncertainty in kinetic parameters calculation; thus, the actual value could be higher as well. In general, the $\beta_{\text {eff }}$ in Thorium-added pebble bed reactor is similar to nominal $\beta$ eff for LEU-fuelled one. Other kinetic parameters show a clearer pattern. The values of prompt neutron lifetime

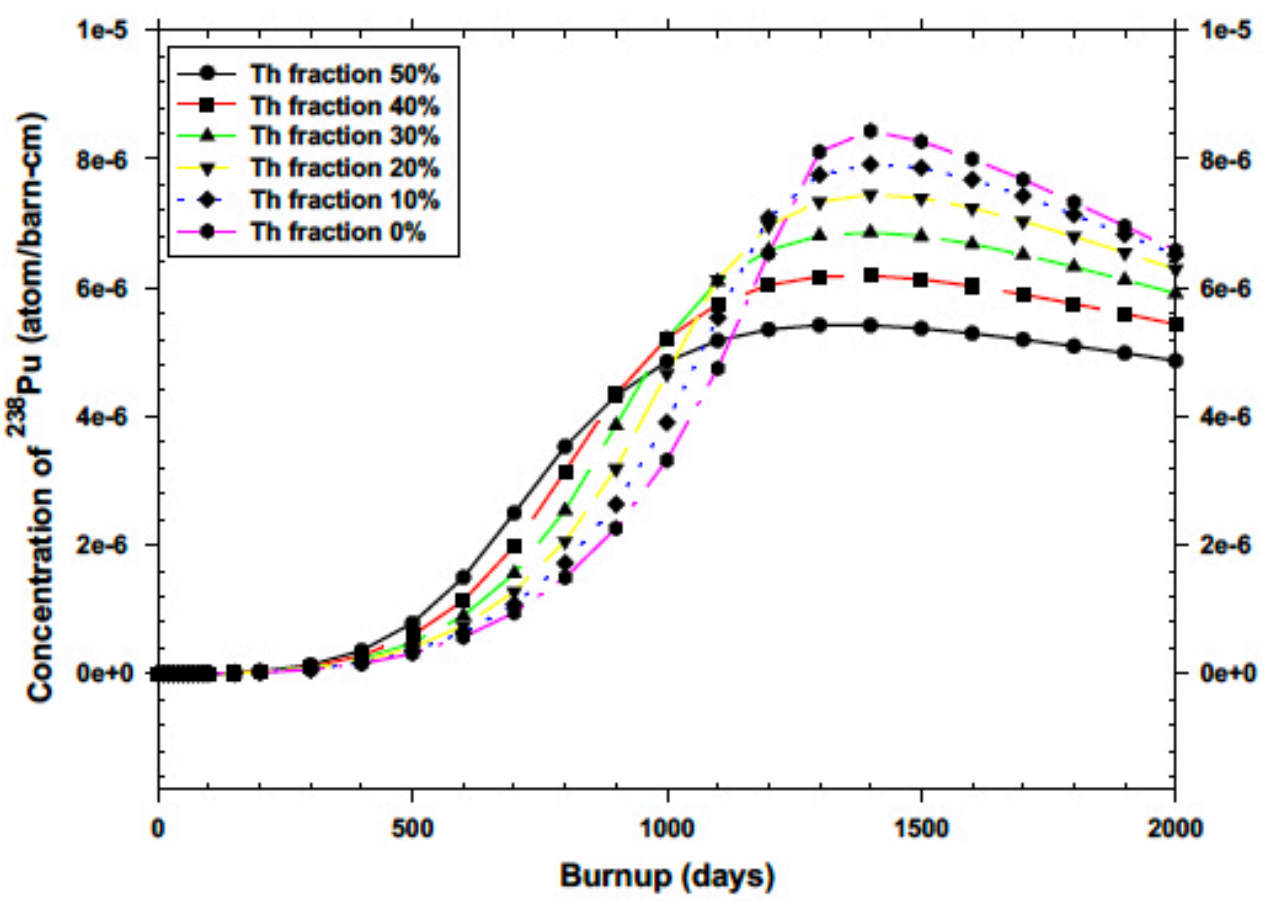

Fig. 6. Concentration of ${ }^{238} \mathrm{Pu}$.

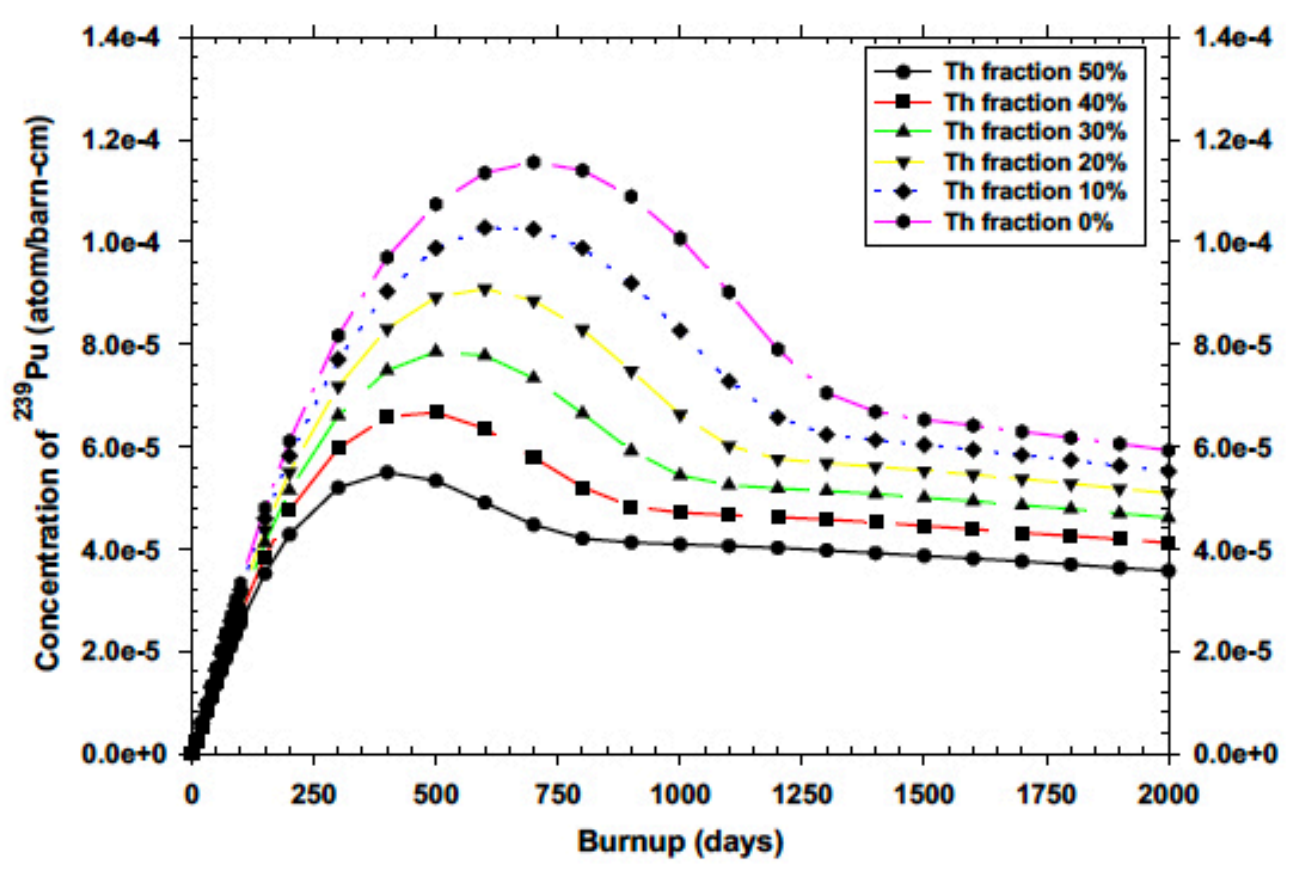

Fig. 7. Concentration of ${ }^{239} \mathrm{Pu}$. 


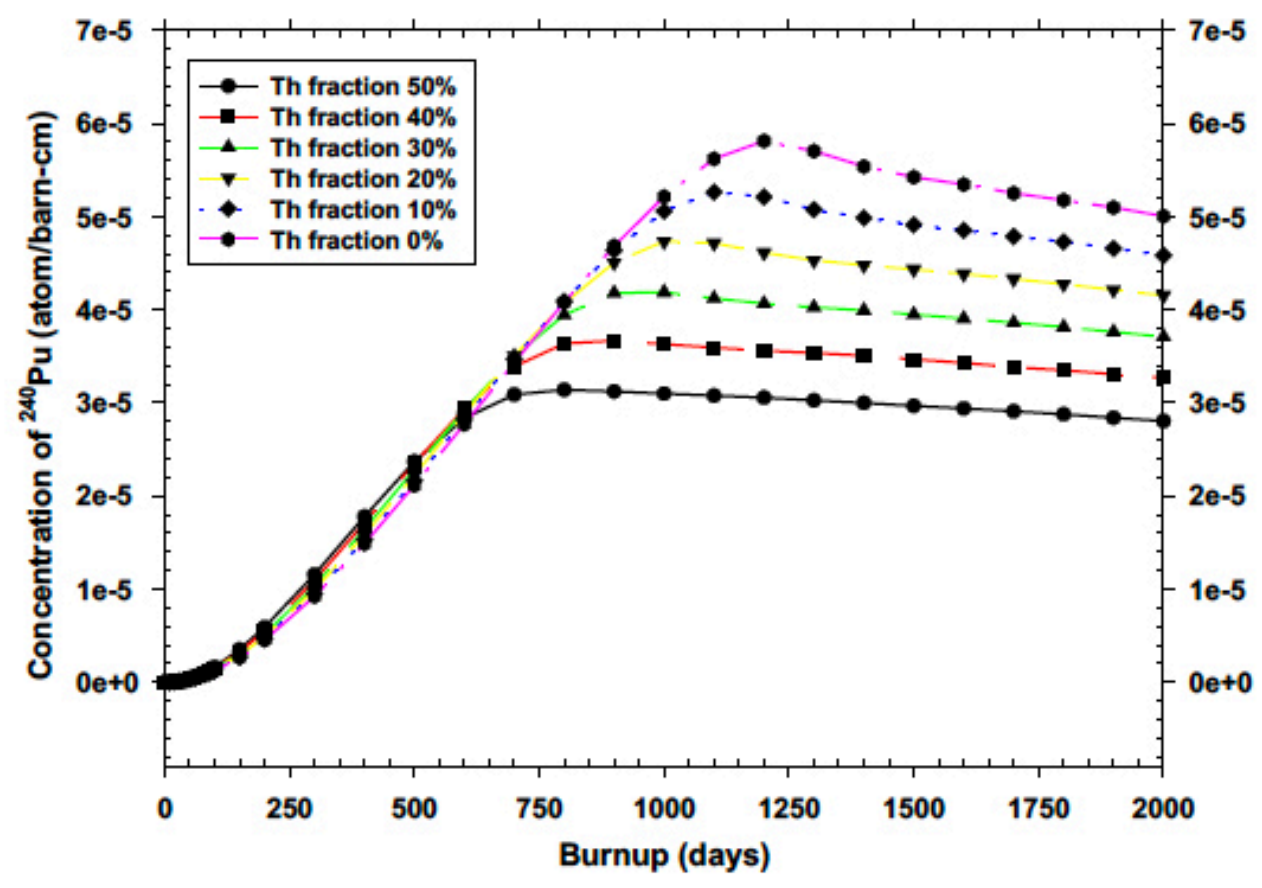

Fig. 8. Concentration of ${ }^{240} \mathrm{Pu}$.

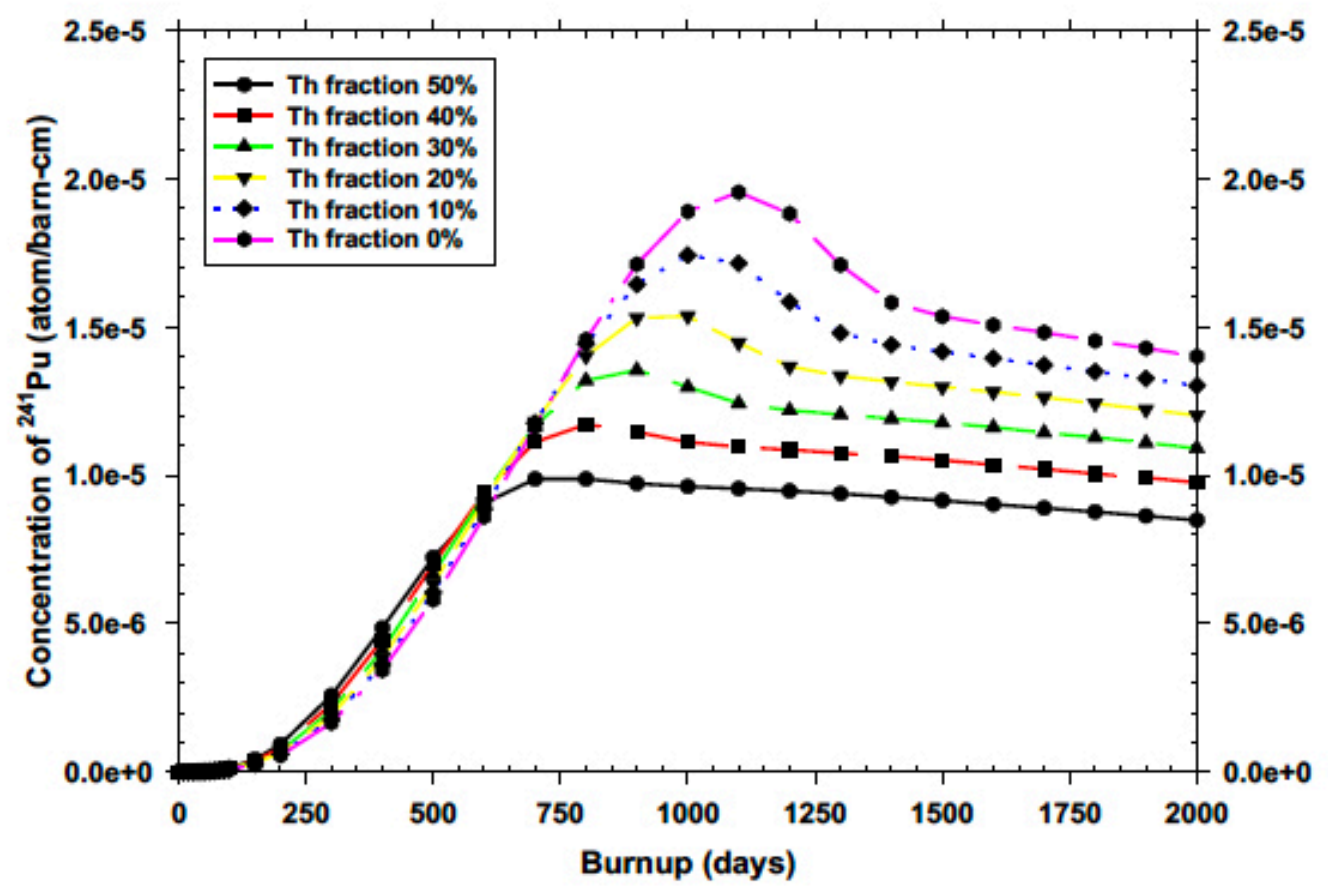

Fig. 9. Concentration of ${ }^{241} \mathrm{Pu}$. 


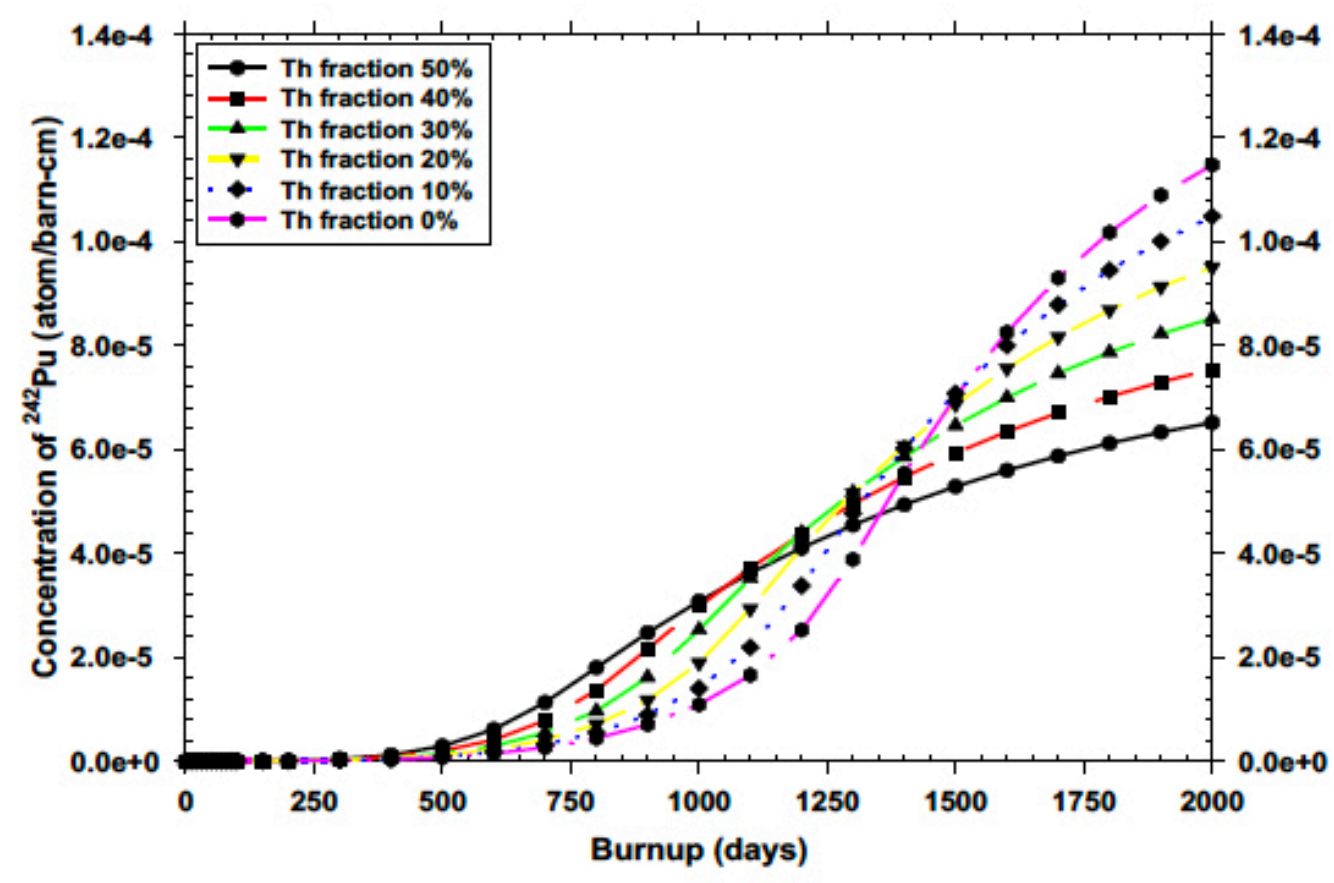

Fig. 10. Concentration of ${ }^{242} \mathrm{Pu}$.

increase with increasing Thorium fraction, which is found in the values of neutron generation time. In this calculation, the temperature was set at $900 \mathrm{~K}$.

Burn-up calculation of infinite multiplication factor $\left(\mathrm{k}_{\mathrm{inf}}\right)$ is shown in Figure 5. As shown in the figure, the LEU-fueled pebble bed reactor has longer effective burn-up days. This is expected since it has the highest fissile load anyway. Increasing Thorium fraction implies that less fissile material can be loaded into the fuel to comply with the $20 \%$ enrichment limit. Meanwhile, ${ }^{233} \mathrm{U}$ conversion from thorium is insufficient to replace the fissioned ${ }^{235} \mathrm{U}$. More on this is explained later.

Another noticeable pattern is apparent after the reactor became subcritical. On the day $2000,50 \%$ Thorium fraction maintains the highest kinf compared to others, while kinf of LEU becomes the lowest. At this point, ${ }^{233} \mathrm{U}$ formation from Thorium takes its effect to maintain higher criticality than LEU-fuelled one. However, this is far under critical value. Thus, for this study, the pattern is pointless. In theory, nevertheless, it shows that ${ }^{233} \mathrm{U}$ formation took considerably more time than plutonium, which must be put into consideration in further studies.

Plutonium is often considered problematic in the nuclear waste management and proliferation issue. Despite pebble bedtype fuel, a high-temperature reactor is no exception, which is already a strong physical and proliferation barrier. The addition of Thorium is expected to reduce plutonium formation in the spent fuel, thanks to its lower atomic and mass number. Plutonium isotopes evolution for each Thorium fraction is shown in Figures 6 to 10 .

For all plutonium isotopes, at day 2000, it is expected that the $0 \%$ Thorium fraction has the highest plutonium concentration, despite different buildup patterns. While ${ }^{239} \mathrm{Pu},{ }^{240} \mathrm{Pu}$, and ${ }^{241} \mathrm{Pu}$ in the $0 \%$ Thorium fraction are constantly the fastest-growing, ${ }^{238} \mathrm{Pu}$ and ${ }^{242} \mathrm{Pu}$ are initially building up more slowly. As the Thorium fraction increases, plutonium buildup slows down. Its production peaks at lower burn-up days and then reduces accordingly, apart from ${ }^{242} \mathrm{Pu}$ has not yet reached its peak.

The aforementioned figures show that Thorium addition is indeed reducing plutonium generation. However, the reduction is not linear to the Thorium fraction in the fuel. The reason is that, even in $50 \%$ Thorium fraction, ${ }^{239} \mathrm{Pu}$ 


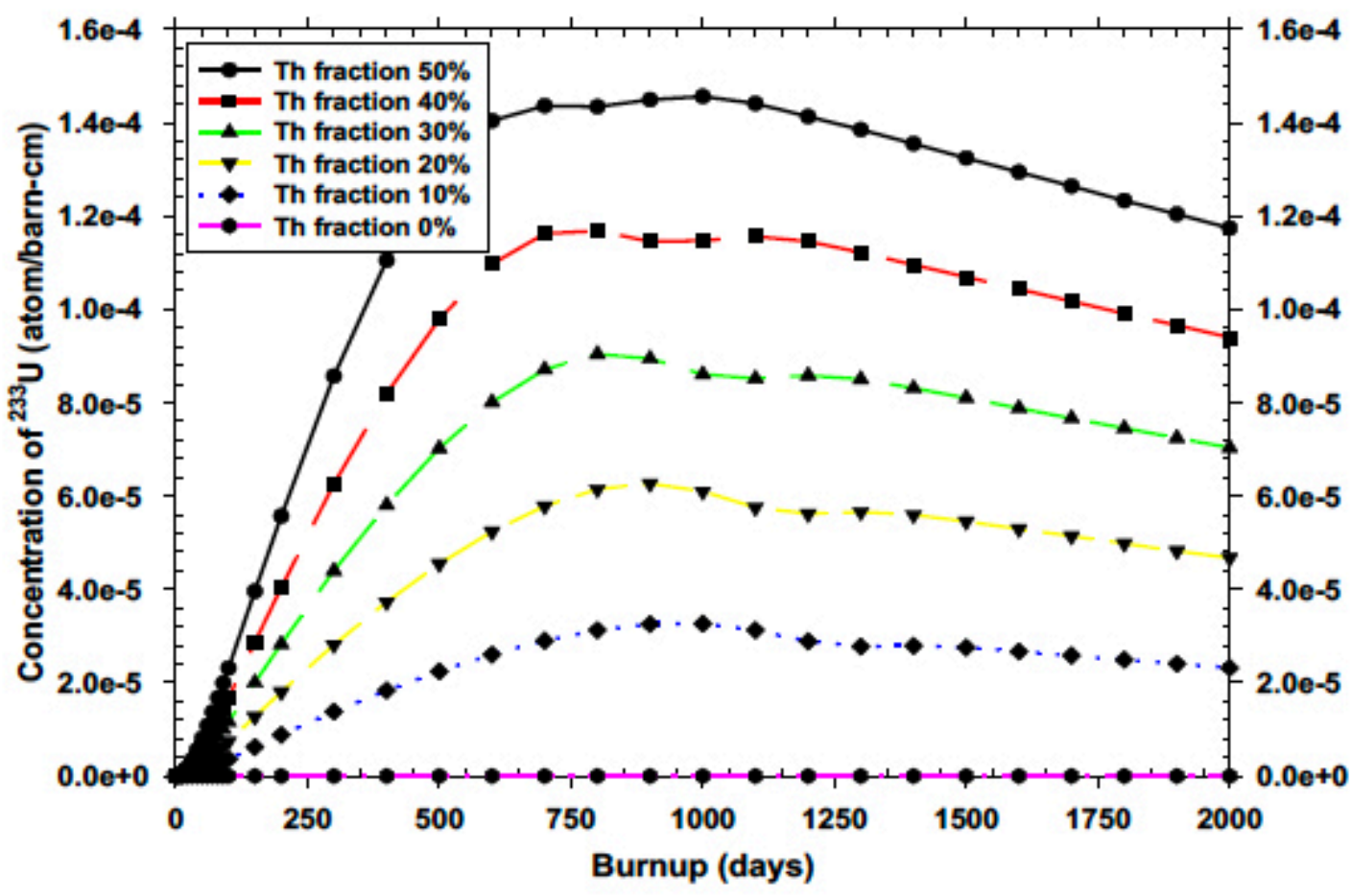

Fig. 11. Concentration of ${ }^{233} \mathrm{U}$.

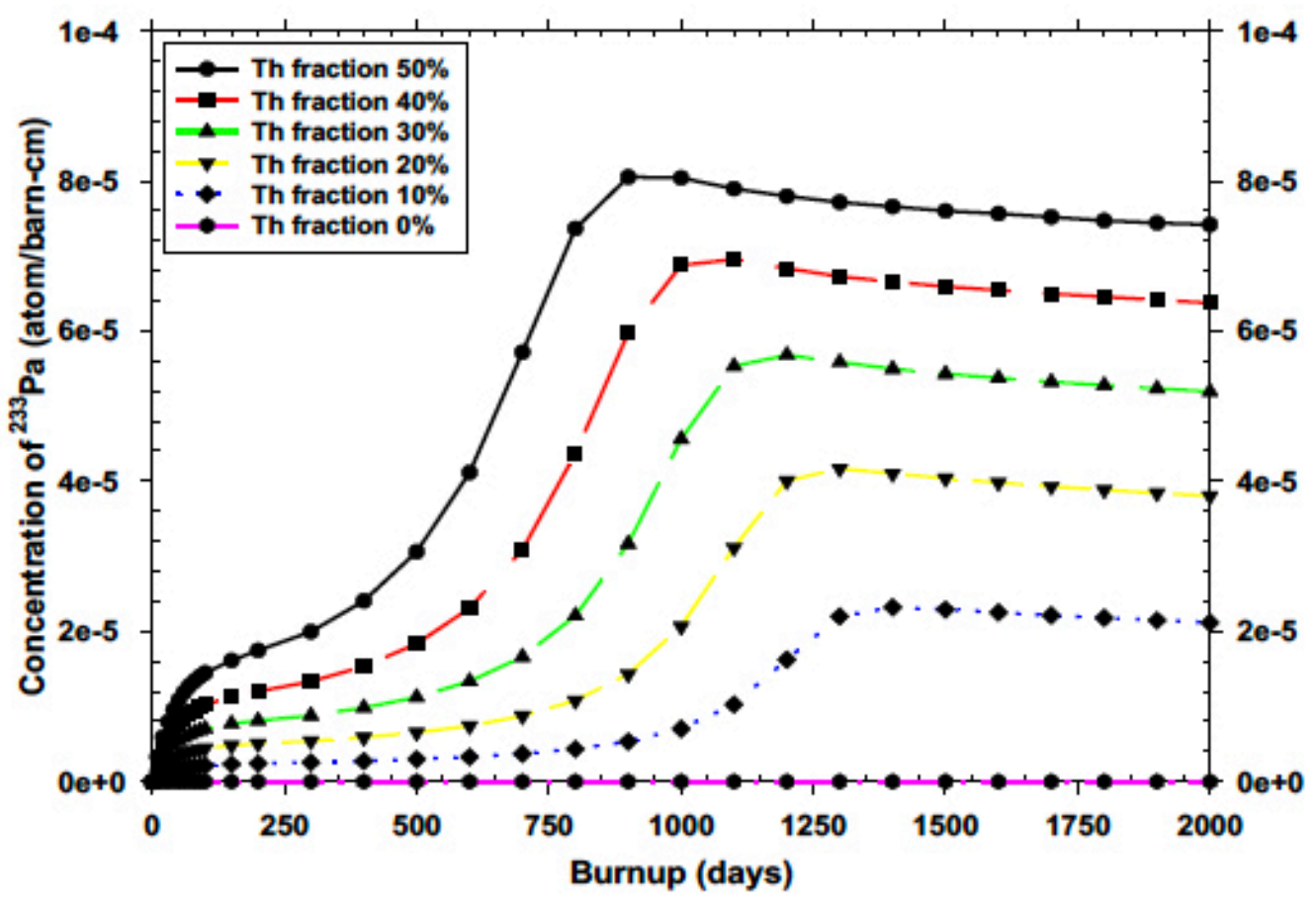

Fig. 12. The concentration of $233 \mathrm{~Pa}$. 


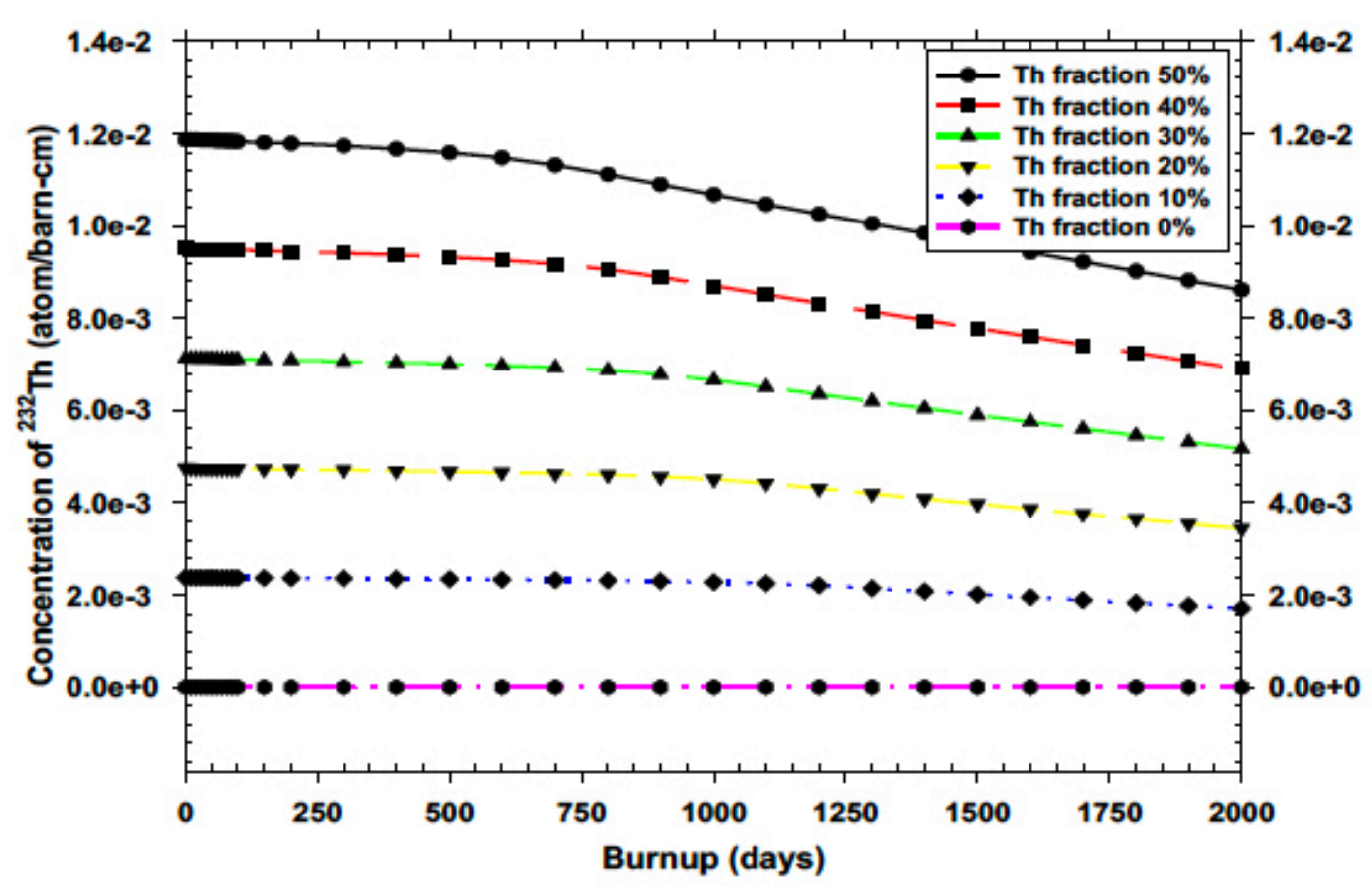

Fig. 13. Concentration of ${ }^{232} \mathrm{Th}$.

into unusable ${ }^{234} \mathrm{U}$, reducing ${ }^{233} \mathrm{U}$ conversion efficiency. The latter is especially important since the MCNP6 calculation ignores the fuel recirculation system inherent to the pebble bed high-temperature reactor. In reality, fuel pebble is periodically discharged, thus allowing ${ }^{233} \mathrm{~Pa}$ to decay without capturing neutrons.

The total concentration of ${ }^{233} \mathrm{U}+{ }^{233} \mathrm{~Pa}$ is not three times larger than ${ }^{239} \mathrm{Pu}$, despite the larger capture cross-section of Thorium. Apart from

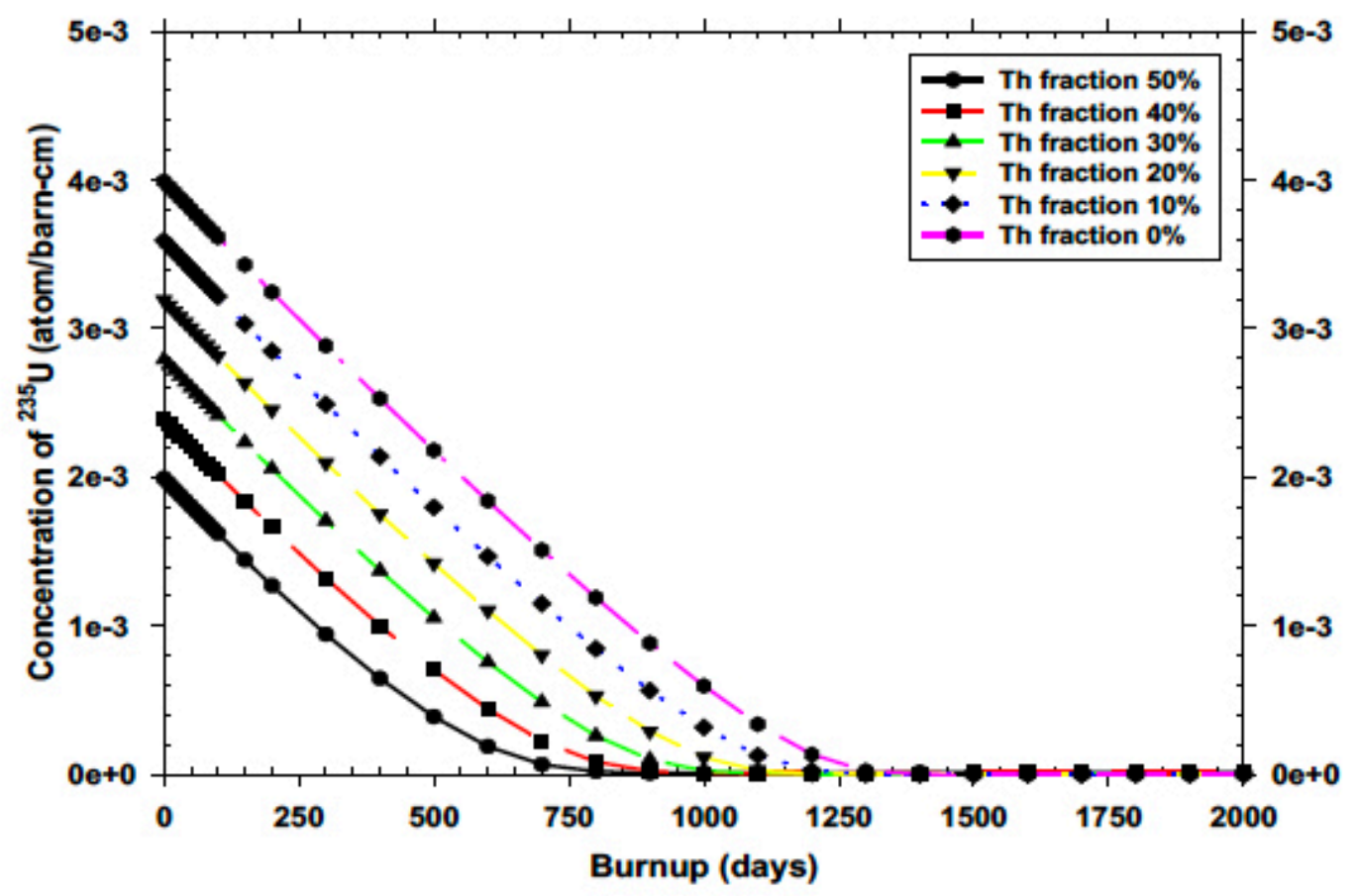

Fig. 14. Concentration of $235 \mathrm{U}$. 


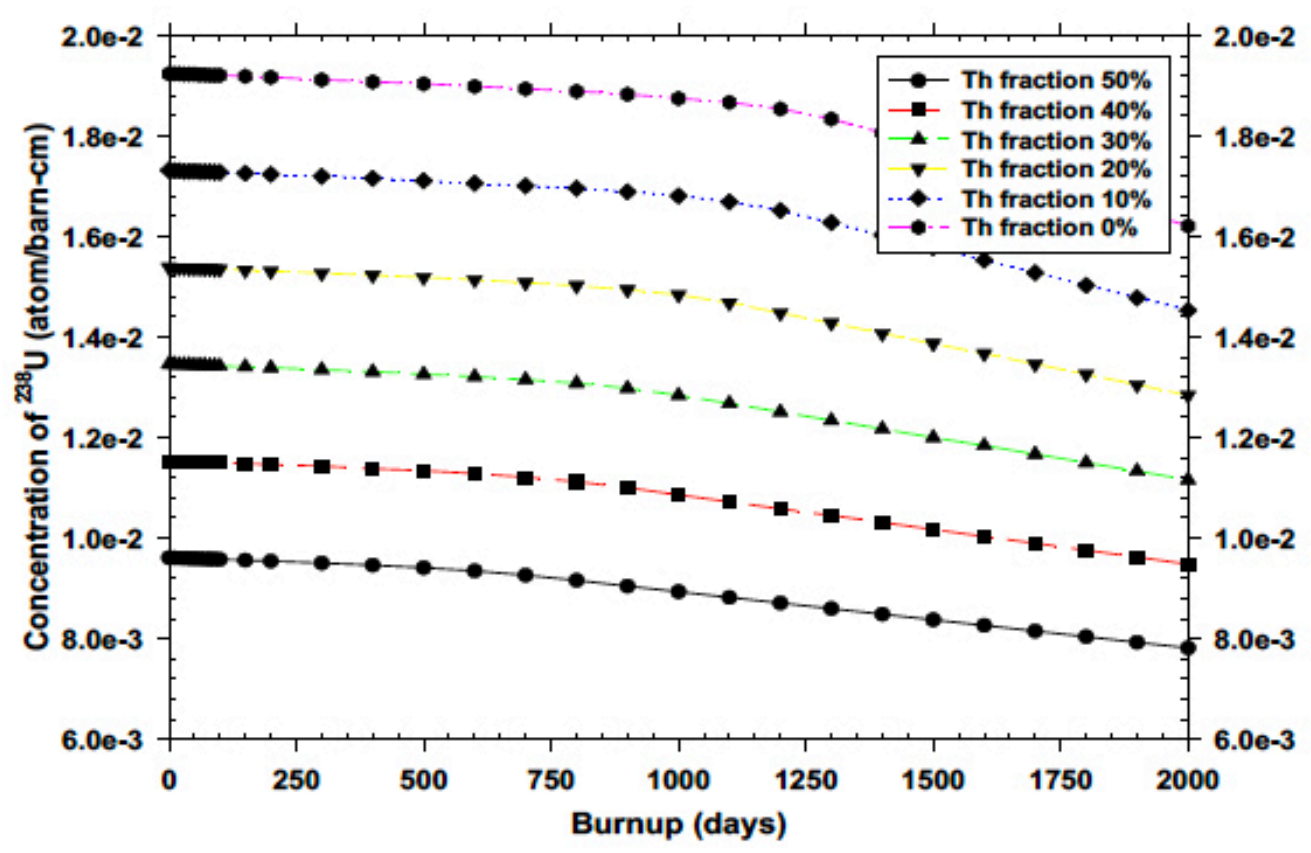

Fig. 15. Concentration of ${ }^{238} \mathrm{U}$.

the reason mentioned in the previous paragraph, another possible explanation is that Thorium works better in the harder spectrum. In a heavily thermalized reactor like a pebble bed hightemperature reactor, Thorium may not be as effective as capturing a neutron and converting them into fissile material. The possible selfshielding effect might further exacerbate this since the fuel kernel radius is not altered.

Meanwhile, ${ }^{233} \mathrm{U}$ and ${ }^{233} \mathrm{~Pa}$ concentrations peaked approximately at day 800-1400, with the latter peaked at later days. For several Thorium fractions, the peaks are well beyond their criticality limit. Therefore, although the bred ${ }^{233} \mathrm{U}$ is considerably large, it is pointless in practical timescale. This shows the constraint of Thorium addition in the same fuel kernel. The 20\% enrichment limit necessitates a lower fissile load for a higher Thorium fraction, which is disadvantageous in maintaining long criticality. This factor must be considered when discussing the possibility of Thorium addition in the pebble-bed high-temperature reactor.

Thorium concentration decreased fastest in 50\% Thorium fraction, as shown in Figure 13. This is expected since Thorium is the most dominant fertile isotope. Thorium decrease is slower in lower fraction as ${ }^{238} \mathrm{U}$ became the dxominant fertile.

Figures 14 and 15 illustrate the evolution of ${ }^{235} \mathrm{U}$ and ${ }^{238} \mathrm{U}$. The figures imply that ultimately ${ }^{235} \mathrm{U}$ is still the main contributor of fission even in Thorium-added hightemperature reactor. ${ }^{235} \mathrm{U}$ concentration reduction is proportional to $\mathrm{k}_{\text {inf }}$ change over time. ${ }^{233} \mathrm{U}$ conversion from Thorium practically plays almost no part in maintaining criticality, owing to the factors mentioned previously; significantly lower initial fissile load of Thorium-added fuel and longer precursor isotope half-life. In high Thorium fraction (above 30\%), the reactor became subcritical long before ${ }^{233} \mathrm{U}$ buildup is sufficient to maintain criticality.

Meanwhile, in low Thorium fraction (30\% and below), ${ }^{233} \mathrm{U}$ buildup is insufficient anyway to compensate for the loss of reactivity due to ${ }^{235} \mathrm{U}$ depletion. Nonetheless, it is shown that ${ }^{233} \mathrm{U}$ and ${ }^{233} \mathrm{~Pa}$ concentrations are larger than fissile plutonium in $40 \%$ and $50 \%$ Thorium fraction at all times. The remaining issue is that ${ }^{235} \mathrm{U}$ loading cannot be higher due to enrichment constraint, prohibiting a high fraction of Thorium from being loaded into the same fuel kernel as LEU. 


\section{Conclusion}

A study on the implication of Thorium fraction on neutronic parameters of pebble bed reactor has been conducted using MCNP6 code based on ENDF/B-VII library. The calculation results show that the addition of Thorium in pebble fuel resulted in a generally more negative total temperature coefficient of reactivity. Among the kinetic parameters, prompt neutron lifetime and neutron generation time are longer, ensuring that the Thorium-added pebble bed reactor can be controlled more easily. Notwithstanding, the advantages of Thorium addition in this study ended here, as burn-up calculations show that Thorium-added fuels are unable to stay critical longer than LEU. This is because fissile loading is reduced when the Thorium fraction increases, whilst ${ }^{233} \mathrm{U}$ conversion from Thorium is insufficient to compensate for the lost fissile. To ensure Thorium has a meaningful share in fission events within the fuel, the fraction must be kept at least $40 \%$. If the initial fissile load can be kept the same as LEU-fuelled pebble bed reactor, a minimum of $40 \%$ Thorium fraction can potentially lengthen fuel residence time since it contributes more to fission than ${ }^{239} \mathrm{Pu}$. Nevertheless, since maintaining the same initial fissile load is constrained by the ${ }^{235} \mathrm{U}$ enrichment limit, introducing Thorium in the same fuel kernel maybe not the best way to exploit Thorium potential in a pebble bed reactor. Therefore, other strategies must be pursued.

\section{ACKNOWLEDGMENTS}

The authors wish to give sincere thanks to Dr. Ir. M. Dhandhang Purwadi, M.T., and Dr. Syaiful Bakhri for their encouragement and support in completing this research work. This work was funded by the Government of the Republic of Indonesia through DIPA PTKRN-BATAN FY 2020.

\section{References}

Alzamly, M.A.; Aziz, M.; Badawi, A.A. et al. (2020). Burn up analysis for HTR10 reactor core loaded with uranium and thorium oxide. Nuclear Engineering and Technology, 52:674-680.

Björk, K.I. (2015). Thorium fuels for light water reactors. $\mathrm{Ph}$. D. thesis, Chalmers University of Technology, Göteborg, Sweden.

Chadwick, M.B.; Obložinský, P.; Herman, M. et al. (2006). ENDF/B-VII: nextgeneration evaluated nuclear data library for nuclear science and technology. Nuclear Data Sheets, 107:2931-3060.

GIF (2010). Use of thorium as the nuclear fuel cycle. Generation IV International Forum, 1-13.

Gintner, S.K. (2010). Thorium-based fuel cycle: saving uranium in a $200 \mathrm{MW}$ th pebblebed high-temperature reactor. Master thesis, North-West University, Potchefstroom, South Africa.

Goorley, J.T.; James, M.R. \& Booth, T.E., et al. (2013). Initial MCNP6 Release Overview - MCNP6 version 1.0. LAUR-13-22934, Los Alamos National Laboratory.

Hosseini, S.A. \& Athari-Allaf, M. (2012). Implementation and benchmarking of ENDF/B-VII based library for PBM reactor analysis with MCNP4c. Progress in Nuclear Energy, 60:27-30.

Hosseini, S.A. \& Athari-Allaf, M. (2016). Effects of the wallpaper fuel design on the neutronic behavior of the HTR-10. Kerntechnik, 81(6):627-633.

IAEA-TECDOC-1450. (2005). Thorium fuel cycle-Potential benefits and challenges. International Atomic Energy Agency. 
Irwanto, D.; Obara T. (2012). Burn up characteristics and fuel cycle economics of mixed uranium-thorium fuel in a simplified small pebble bed reactor, Journal of Nuclear Science and Engineering (4):222-229.

Jing, X. \& Sun, Y. (1998). Benchmark Problem of the HTR-10 Initial Core Draft Version. Institute of Nuclear Energy Technology (INET), Beijing, China.

Lebenhaft, J.L. (2001). MCNP4B modeling of pebble-bed reactors. MSNE Thesis, Massachusetts Institute of Technology, Massachusetts, USA.

Setiadipura, T.; Irwanto, D. \& Zuhair (2015). Preliminary neutronic design of high burn up OTTO cycle pebble bed reactor. Atom Indonesia, 41(1):7-15.

Suwoto; Luthfi., W.; Adrial, H. \& Zuhair. (2018). Study on Temperature Coefficient of Reactivity for Pebble Bed Reactor with Thorium Fuel. International Journal of Mechanical Engineering and Technology, 9(13): 1410-1419.

Wahid, L.; Setiadipura, T.; Zuhair; Suwoto \& Bakhri, S. (2019). Criticality and Burnup Study on Different TRISO Modelling of HTR Pebble. Journal of Physics: Conference Series 1198022078. doi: 10.1088/1742-6596/1198/2/022078

Wilson, W.B.; Dyadechko, V.; England, T.R. et al. (2006). A Manual for CINDER90 Version 06.1 Codes and Data. Los Alamos National Laboratory, Draft Report, Los Alamos, NM.

Wu, Z.; Lin, D. \& Zhong, D. (2002). The design features of the HTR-10. Nuclear Engineering and Design, 218:25-32.http:// dx.doi.org/10.1016/S00295493(02)00182-6

Xia, B. \& Li, F. (2013). Preliminary study on the feasibility of utilizing the thermal fissile breeding capability of the Th-U fuel. cycle in HTR-PM. Proceedings of the 2013 21st International Conference on Nuclear Engineering (ICONE21), ICONE21-16460

Zuhair; Suwoto; Setiadipura, T. \& Kuijper, J.C. (2019a). Study on the characteristics of effectively delayed neutron fraction ( $\beta$ eff) for a pebble-bed reactor with plutonium fuel. Iranian Journal of Science and Technology, Transactions A: Science, 1-9 doi: 10.1007/s40995-019-00772-8

Zuhair; Suwoto; Setiadipura, T. \& Kuijper, J.C. (2019b). The effects of fuel type on control rod reactivity of pebble-bed reactor. Nukleonika, 64(4):131-138. doi: 10.2478/nuka-2019-0017

Zuhair; Suwoto; Setiadipura, T. \& Su'ud, Z. (2020). Study on MCNP6 model in the calculation of kinetic parameters for pebble bed reactor. Acta Polytechnica, 60(2):175184. doi: 10.14311/AP.2020.60.0175

$\begin{array}{lr}\text { Submitted: } & 20 / 06 / 2020 \\ \text { Revised: } & 16 / 09 / 2020 \\ \text { Accepted: } & 27 / 09 / 2020 \\ \text { DOI: } & 10.48129 / \text { kjs.v48i3.9984 }\end{array}$

